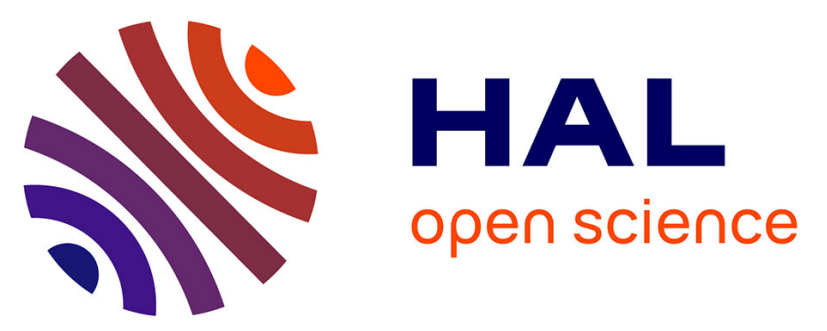

\title{
Assessment of pulmonary tissue responses in pigs challenged with PRRSV Lena strain shows better protection after immunization with field than vaccine strains
}

Thibaut Larcher, Christelle Fablet, Patricia Renson, Déborah Menard, Caroline Hervet, Georges Saade, Catherine Belloc, Olivier Bourry, François Meurens

\section{- To cite this version:}

Thibaut Larcher, Christelle Fablet, Patricia Renson, Déborah Menard, Caroline Hervet, et al.. Assessment of pulmonary tissue responses in pigs challenged with PRRSV Lena strain shows better protection after immunization with field than vaccine strains. Veterinary Microbiology, 2019, 230, pp.249-259. 10.1016/j.vetmic.2019.01.022 . hal-02061157

\author{
HAL Id: hal-02061157 \\ https://hal.science/hal-02061157
}

Submitted on 22 Oct 2021

HAL is a multi-disciplinary open access archive for the deposit and dissemination of scientific research documents, whether they are published or not. The documents may come from teaching and research institutions in France or abroad, or from public or private research centers.
L'archive ouverte pluridisciplinaire HAL, est destinée au dépôt et à la diffusion de documents scientifiques de niveau recherche, publiés ou non, émanant des établissements d'enseignement et de recherche français ou étrangers, des laboratoires publics ou privés.

\section{(ㅇ)(1) $\$$}

Distributed under a Creative Commons Attribution - NonCommerciall 4.0 International 
1 Assessment of pulmonary tissue responses in pigs challenged with PRRSV Lena strain

2 shows better protection after immunization with field than vaccine strains

3

4

5 Thibaut Larcher $^{1}$, Christelle Fablet ${ }^{2,3}$, Patricia Renson ${ }^{2,3,4}$, Déborah Ménard ${ }^{5}$, Caroline 6 Hervet $^{5}$, Georges Saade ${ }^{5}$, Catherine Belloc ${ }^{5}$, Olivier Bourry ${ }^{2,3 \S}$, and François Meurens ${ }^{5 \S^{*}}$

7

8

$9 \quad{ }^{1}$ PAnTher, INRA, Oniris, Université Bretagne Loire, 44307, Nantes, France

$10{ }^{2}$ Agence Nationale de Sécurité Sanitaire Alimentation Environnement Travail (Anses), BP 53,

22440 Ploufragan, France

${ }^{3}$ Université Bretagne Loire, 44307, Nantes, France

${ }^{4}$ IFIP-Institut du porc, 5 Rue Lespagnol, 75020 Paris, France

${ }^{5}$ BIOEPAR, INRA, Oniris, Université Bretagne Loire, 44307, Nantes, France

${ }^{\S}$ Contributed equally to this work

*Corresponding author: Email: francois.meurens@oniris-nantes.fr; Phone: +33 2406877 02;

Fax: +33240682802.

Short Running Title: Pulmonary response to Lena PRRSV strain in immunized pig

Keywords: PRRSV; lung; immune response; chemokine; chemokine receptor; tissue scoring; genotype 1.3 strains 


\section{ABSTRACT}

The porcine reproductive and respiratory syndrome virus (PRRSV) is plaguing porcine production. Previously piglets were immunized with a PRRSV-1 commercial modified live virus vaccine (MLV1), a PRRSV-2 MLV (MLV2) or a Western European strain (Finistere: Fini) to assess and compare the protection brought by these strains upon challenge with virulent Lena strain. Lena viremia was reduced in all the immunized groups with a slightly higher level of protection following immunization with Fini. Using lung samples collected from the same experiment, tissue response to Lena challenge was assessed at the acute and chronic stages of infection. A pre-immunization with any one of the three PRRSV strains globally exacerbated microscopic lung lesions. Ten days post-challenge (DPC), MLV1 group score was higher than unimmunized group score and 42 DPC, MLV2 group score was higher than in unimmunized group. Lowest lung Lena viral loads were measured in Fini group. Using principal component analysis, we showed 10 DPC that the lesion score was positively correlated with chemokine receptors and negatively correlated with viral load. Forty-two DPC, variables for lesion score, IL6, IL8, and CCL20 transcripts were positively correlated together and negatively correlated with CCL28, CXCL6, and CXCR4 transcripts suggesting a role for the latter ones in the tissue recovery process. In conclusions, our study shows a significant impact of the three immunizations on pulmonary tissue with the best protection against Lena challenge conferred by Fini strain. Furthermore, it gives insight into the interactions between vaccine and Fini strains and the lung upon Lena challenge.

\section{Introduction}


- both members of the Arteriviridae family and Nidovirales order like equine arteritis virus, simian hemorrhagic fever virus, and lactate dehydrogenase-elevating virus - have a huge impact on the porcine production worldwide (Lunney et al., 2016; Snijder et al., 2013). These viruses are able to counteract the innate immune response of the porcine host and induce a disease characterized by respiratory and genital disorders (for a review see (Du et al., 2017; Lunney et al., 2016)). Historically, two genotypes of PRRSV were identified in the late 1980s: genotype 1 in Europe and genotype 2 in Asia and North America (Keffaber, 1989; Lunney et

al., 2016; Wensvoort et al., 1991). These viruses are now classified as two different species. Moreover, different subtypes have been described among PRRSV-1. Subtype 1 strains are mostly low pathogenic strains and circulate primarily in Western Europe even if also present in Asia and North America. Conversely, subtype 3 strains are described as clearly more virulent than subtype 1 strains and have already been identified in Eastern Europe (Weesendorp et al., 2013).

Previously, and to prepare for the possible emergence of a subtype 3 strain in Western Europe, piglets were immunized with a PRRSV-1 commercial modified live virus (MLV) vaccine (MLV1), a PRRSV-2 commercial MLV vaccine (MLV2), and a Western European PRRSV strain (Finistere: Fini), to assess and compare the protection brought by these strains upon challenge with the virulent subtype 3 Lena strain four weeks later (Renson et al., 2017a). Basically, it was observed that the levels of Lena viremia were diminished for all the immunized groups and that the immunization with Fini, MLV1, and MLV2 strains shortened the hyperthermia induced by Lena strain (Renson et al., 2017a). Moreover, in the Fini group, they also observed an improvement in growth performance possibly related to a better cellmediated immune response as suggested by the level of Lena-specific IFN $\gamma$-secreting cells. Thus, it appeared that commercial PRRSV-1 and PRRSV-2 MLV vaccines as well as the field 
strain Finistere could provide partial clinical and virological protection against a challenge with the virulent Lena strain. However, the study focused primarily on clinical and zootechnical parameters, blood viral load, systemic humoral and cellular responses (ELISPOT using peripheral blood mononuclear cells - PBMC). Because PRRSV multiplies mostly in pulmonary alveolar macrophages and to further our understanding of previous results, we performed the following study. Using lung samples collected from the experiment performed by Renson and collaborators (Renson et al., 2017a), we carried out a molecular and histopathological analysis of the immune response of the lung tissues in the different groups of non-immunized and immunized pigs. This lung tissue analysis completes and broadens the previous report.

\section{Materials and methods}

\subsection{Vaccine and virus strains}

Two MLV vaccines were used in the in vivo experiment as described by Renson and collaborators (Renson et al., 2017a): the PRRSV-1 Ingelvac PRRSFLEX ${ }^{\circledR}$ EU vaccine (Boehringer Ingelheim France, Paris, France, 94881 strain, GenBank accession no. KT988004) (MLV1) and the PRRSV-2 Ingelvac ${ }^{\circledR}$ PRRS MLV vaccine (SCS Boehringer Ingelheim Comm, Brussels, Belgium, USA ATCC VR2332 strain, GenBank accession no. EF484033) (MLV2). The PRRSV-1 subtype 1 (1.1) Finistere PRRSV strain (PRRS-FR-200529-24-1, GenBank accession no. KY366411) was isolated in France in 2005 from a herd with reproductive failures in sows. In specific pathogen-free (SPF) pigs, Finistere infection induces a mild clinical expression (Rose et al., 2015). The PRRSV-1 subtype 3 (1.3) Lena PRRSV strain (GenBank accession no. JF802085) was kindly provided by Dr. Hans Nauwynck (University of Ghent, Belgium). The Lena strain was isolated in Belarus in 2007 from a herd 
122

123

with mortality, reproductive failures and respiratory disorders (Karniychuk et al., 2012). The Finistere and the Lena strains were propagated and titrated on pulmonary alveolar macrophages as previously described (Renson et al., 2017a).

\subsection{Experimental setting}

The experimental setting has been described previously (Renson et al., 2017a). Briefly, 41 four-week-old pure Large White piglets coming from a specific pathogens free nucleus herd were housed in biosecurity level-3 air-filtered animal facilities. The 41 piglets were randomly distributed according to their origin, weight and gender and assigned to five groups housed in separate rooms (Table I). At 6 weeks of age (D-27), 9 piglets were vaccinated intramuscularly with either the MLV1 (minimum dose $10^{4.4}$ TCID50/piglet) or the MLV2 vaccine (minimum dose $10^{4.9}$ TCID50/piglet) (MLV1 and MLV2 group). At the same time, 7 piglets were inoculated intranasally with the PRRSV Finistere strain $\left(5 \times 10^{5} 50 \%\right.$ tissue culture infectious dose (TCID50) per piglet) (Fini group). Intranasal inoculation was performed by direct instillation of the virus suspension in each nostril, using a $5 \mathrm{ml}$ syringe without needle. At 10 weeks of age (D0), all the piglets from the Fini, MLV1, and MLV2 groups were challenged intranasally with the Lena strain (genotype $1.3,5 \times 10^{5}$ TCID50/piglet). At the same time, 8 non-immunized piglets were also inoculated with the Lena strain (non-immunized, NI group) and 8 non-immunized piglets were mock inoculated (control group).

All the animal experiments were authorized by the French Ministry for Research (authorization no. 2015060113297443_v1) and approved by the national ethics committee (authorization no. 07/07/15-3).

\subsection{Sampling/necropsy and histopathological observations}



Lena infection (10 \pm 1 days post-challenge, DPC) and the remaining pigs at the end of the follow-up (42 $\pm 1 \mathrm{DPC})$. Then, pieces from the dorsal diaphragmatic lobe of the lung were collected for each pig and frozen at $-80^{\circ} \mathrm{C}$ or formalin-fixed. Fixed samples were then paraffin-embedded, and sectioned ( $5 \mu \mathrm{m}$ thick) before staining with a routine hematoxylineosin-saffron (HES) stain (Riva et al., 2014). The microscopic observation was performed by a trained veterinary pathologist who was blind to the experimental setting. A previously published histopathological lung lesion scoring method was used (Jung et al., 2007) and an adapted lesion scoring method including subacute lesions was added. Briefly, in the adapted lesions scoring method the following criteria were scored (i) thickening of alveolar septa (ranging from 0 to 6 , where 0 is normal appearance, 1 is mild focal or multifocal, 2 is mild diffuse, 3 is moderate focal or multifocal, 4 is moderate diffuse, 5 is severe focal or multifocal, and 6 is severe diffuse interstitial pneumonia); (ii) accumulation of material in respiratory airways (ranging from 0 to 3 , where 0 is normal appearance and 3 is severe); (iii) peribronchiolar or perivascular inflammatory cells cuffing (ranging from 0 to 3 , where 0 is normal appearance and 3 is severe); (iv) proliferative subacute bronchiolitis (ranging from 0 to 3 , where 0 is normal appearance, 1 is diffuse thickening, 2 is partially occluding and 3 is obliterative); (v) alveolar emphysema (ranging from 0 to 3 , where 0 is normal appearance, 1 is focal or multifocal, 2 is focally extensive and 3 is diffuse) and (vi) BALT hyperplasia (ranging from 0 to 3 , where 0 is normal appearance and 3 is severe hyperplasia). The total histopathological lung lesion scores ranged from 0 (no abnormalities) to 21 (most severe bronchointerstitial pneumonia) and was expressed as a percentage of the maximal score.

\subsection{Immune gene expression analysis and virus detection in the pulmonary tissue using} quantitative real-time PCR 
To detect immuno-related transcripts (cytokines, chemokines, and chemokine 150 receptors) and PRRSV strains, real-time PCR primers were previously developed (Meurens et al., 2009; Nygard et al., 2007) or designed and optimized using Clone Manager 9 (Scientific \& Educational Software, Cary, NC, USA) and were purchased from Eurogentec (Liège, Belgium) (see Table II for primer list). Pulmonary tissue samples (two pieces of $1 \mathrm{~mm}^{3}$ ) were suspended in Trizol reagent (Invitrogen, Cergy Pontoise, France) with ceramic beads (BioSpec Products, OK, USA) and total RNA was isolated using RNeasy Plus Mini Kit (Qiagen, Courtaboeuf, France). The absence of genomic DNA contamination was verified using prepared RNA as a template for quantitative real-time PCR (qPCR). RNA concentration was determined by measuring optical density at $260 \mathrm{~nm}$ (OD260) and the RNA quality was assessed by calculating OD260/OD280 ratio and by capillary electrophoresis (Agilent 2100 Bioanalyzer, Agilent Technologies Inc., Santa-Clara, USA). cDNA was generated from 100200 ng of RNA per reaction following a previously described method (Meurens et al., 2007). The generated cDNA was stored at $-80^{\circ} \mathrm{C}$. $\mathrm{qPCR}$ was performed using cDNA synthesized with Moloney Murine Leukemia Virus reverse transcriptase (Eurogentec). Diluted cDNA (2X) was combined with primer sets $(0.2 \mu \mathrm{L}$ of $10 \mathrm{mM}$ primer stock) and MESA GREEN qPCR MasterMix (Eurogentec) according to the manufacturer's recommendations. The real time PCR was run on CFX96 Bio-Rad Connect (Bio-Rad, Hercules, CA, USA). The cycling conditions were 1 cycle of denaturation $95^{\circ} \mathrm{C} 5$ minutes (min), followed by 40 cycles of amplification $\left(95^{\circ} \mathrm{C} / 15\right.$ seconds $(\mathrm{s}), 58^{\circ} \mathrm{C}-67^{\circ} \mathrm{C} / 40 \mathrm{~s}$ depending on the selected gene, see

Table II). The fluorescence was automatically measured during the PCR assay. Software CFX manager 3.1 (Bio-Rad) was used to determine the Cycle quantification $(C q)$ in each reaction.

171 A melting curve was elaborated for each primer pair to verify the presence of one gene 172 specific peak. qPCR assays were carried out as previously described using the three most 173 stable reference genes (Delgado-Ortega et al., 2011; Delgado-Ortega et al., 2014; Dobrescu et 
174 al., 2014). Then, qPCR data were expressed as relative values after Genex macro analysis

175 (Bio-Rad) (Vandesompele et al., 2002) using the $C q$ from the samples for the different 176 transcripts.

177 Regarding the Taqman PCR assay, the mix and the conditions were different. Two $\mu \mathrm{L}$ 178 of $2 \mathrm{X}$ diluted cDNA were combined with $5 \mu \mathrm{L}$ of Takyon No Rox Probe MasterMix dTTP 179 blue $2 \mathrm{x}$ (Eurogentec), $0.3 \mu \mathrm{L}$ of each primer $(10 \mu \mathrm{M}), 0.25 \mu \mathrm{L}$ of probe $(10 \mu \mathrm{M})$, and water 180 for a final volume of $10 \mu \mathrm{L}$. The qPCR conditions were $95^{\circ} \mathrm{C}$ for 3 min followed by 40 cycles 181 with denaturation at $95^{\circ} \mathrm{C}$ for $6 \mathrm{~s}$ and annealing/elongation for $15 \mathrm{~s}$ at $60^{\circ} \mathrm{C}$. The Taq-man 182 PCR was also run on a CFX96 Bio-Rad Connect (Bio-Rad).

\subsection{Statistical analysis}

Comparison of histological lesions, immune responses and Lena strain viral load between experimental groups

Data for the comparison of differences in relative mRNA expression between experimental groups were expressed as relative values. One-Way ANOVA was used to detect differences in relative mRNA expression and composite score between experimental groups. To account for the non-normal distribution of the data, all data were sorted by rank status prior to ANOVA statistical analysis. Tukey's test was used to compare the means of the ranks among the groups. $P$-values less than 0.05 were considered significant. All statistical analyses were done using computer software Prism 6 for Windows (version 6.02; GraphPad Software, San Diego, CA, USA).

\section{Relationships between immunological, histological and virological descriptors}

Associations between the relative mRNA expressions of different genes involved in the immune response, the histological Jung score and the Lena strain viral load in the lungs of MLV1, MLV2, Fini and Lena groups were investigated by principal component analysis 
(PCA) at 10 DPC (R free software, available from: http://www.R-project.org). Two outliers (one pig from MLV1 and one from MLV2 group) with the highest values on the level of expression of chemokines receptors transcripts and having a singular immune response quite different from the other pigs (confirmed by a clustering analysis, data not shown) were discarded from the analysis to better described the associations between the variables.

Due to the absence of detection of Lena strain 42 DPC in all groups, the associations between the set of immune response descriptors and the histological score were assessed by PCA at this time point.

The main objective in PCA is to detect the associations within a set of continuous variables in a small number of dimensions and to provide a low-dimensional (often twodimensional) graphical representation of these associations (Joliffe, 2002). Each variable is represented by an arrow inside a correlation circle, the higher the length of the arrow, the higher the variable contribution to the inertia. The angle between arrows indicates the degree of correlation between the variables, the smaller the angle the higher the correlation. An angle of $90^{\circ}$ indicates that the two variables are independent and an angle of $180^{\circ}$ shows a negative correlation.

\section{Results}

\subsection{Viral replication/load in the lung tissue was lower in the Fini group than in the other} immunized groups

At 10 DPC, except in control group, the PRRSV genome was detected without any significant difference between groups $(p>0.05)$. Because PRRSV universal primers could not differentiate the strains used for immunization and challenge, we had to use primers specifically designed for the detection of Lena challenge strain to assess the impact of 
immunization on Lena virus load. With these primers, the Lena viral load was found to be significantly lower in the Fini group than in the other immunized and non-immunized control groups ( $p<0.05$, Figure 1). Using PRRSV universal primers, as well as Lena-specific primers, no PRRSV genome was detected for Lena-infected groups 42 DPC (Figure 1).

\subsection{Histologic lesions: Pre-immunization with MLV strains showed higher composite scores than with Fini strain}

To evaluate the tissular impact of the Lena strain challenge after immunization with another PRRSV strain, lung samples were observed histologically and lesions were scored using a previously published score grid (Jung et al., 2007) adapted to take into account subacute lesions including proliferative bronchiolitis and alveolar emphysema (see Table III). Most control animals (7 out of 8 ) displayed mild interstitial pneumonia (scored $28.7 \pm 7.8 \%$ and $27.5 \pm 4.3 \% 10$ and 42 DPC, respectively) mainly represented by a slight thickening of alveolar walls due to infiltration by some inflammatory cells (Figures 2 and 3). These findings indicate a low background of inflammation which may be associated with dust aspiration.

In contrast, all animals (8 out of 8 ) inoculated with Lena displayed severe and extended lesions of interstitial bronchopneumonia resulting from the thickening of alveolar septa by a mixed population of inflammatory cells and from respiratory airway alterations including the presence of intra-luminal necrotic material, epithelium hyperplasia and peribronchiolar inflammatory cell infiltration.

A pre-immunization with one of the three studied PRRSV strains globally exacerbated microscopic lung lesions: The MLV1-immunized group composite score was higher than the unimmunized group 10 DPC $(p<0.05)$ and the MLV2-immunized group score was higher than the unimmunized group 42 DPC ( $p<0.01$ ) (Figures 2A and 3). MLV1, MLV2 and Finiimmunized animals displayed prominent alveolar wall thickening and respiratory airway 
obstruction by intraluminal materials. In MLV1-immunized animals, we also observed a

250 decreasing trend in the histopathological score between the studied time-points (mean score $70.2 \pm 9.7 \%$ and $52.2 \pm 12.7 \% 10$ and $42 \mathrm{DPC}$, respectively) corresponding mainly to a

252

253

254

255

256

257

258

259

260

261

262

263

264

265

266

267

268

269

270

271

272 clearance of the airway debris. Specifically, in MLV1- and MLV2-immunized animals, some foci of necrotic cells admixed with degenerated neutrophils were scattered in lung parenchyma 10 DPC (Figure 2B), and a prominent BALT hyperplasia was identified 42 DPC.

\subsection{Analysis of the lung immune response in the different groups of pigs}

In order to analyze in more detail, the lung response to Lena strain challenge in preimmunized pigs, we assessed the expression of various immuno-related transcripts in the lung tissue (see Table II and Figure 4). Regarding transcripts associated with CCR6, IL10, IFN $\gamma$, and TNF $\alpha$ no statistically significant differences were observed between groups $(p>0.05$, data not shown). On the contrary, transcripts associated with chemokines IL8/CXCL8, CCL20, and CXCL6 were more expressed in MLV1, MLV2, and NI groups 10 DPC than in Fini and control groups (Figure 4A). Most of the time, the observed differences were statistically significant $(p<0.05)$. Because we observed an induction of chemokine genes, we next assessed the expression of various CXC chemokine receptors (CXCR1-7) transcripts (Figure 5 and data not shown for CXCR7). Differences in transcript expression were observed. For CXCR2, CXCR5, and CXCR6 transcripts 42 DPC there were trends $(p>0.05)$ for a higher expression in MLV1 and MLV2 groups than in other groups (Figure 5). We then evaluated the transcript expression of the mucosal chemokine CCL28 and its two main receptors, CCR3 and CCR10 (Figure 4B). Again, a trend for a higher expression of some transcripts (CCL28, CCR3, and CCR10) in MLV1 and MLV2 groups 42 DPC than in other groups was observed but the difference was not statistically significant $(p>0.05)$. Moreover, 
273 the highest level of expression of CCL28 transcripts was observed in the MLV1 group 10

274 DPC (Figure 4B).

275 Relationships between immunological, histological and virological descriptors in pre-

276

277

278

279

\section{immunized and/or challenged groups}

The PCA revealed three groups of associations between variables describing the levels of immunological, histological and virological lung responses 10 DPC (Figure 6A). One group of positively correlated variables (top left corner of the map) comprised the level of expression of chemokines (CCL20, CCL28, CXCL6, IL8/CXCL8) and chemokine receptor transcript CXCR1. A second group of positively correlated variables, located in the right part of the map, was mainly independent from the first group and was related to the level of expression of the transcripts of all other chemokine receptors. To a lesser degree the histological Jung score was positively correlated with this second group of variables. The second group of variables was negatively correlated with the Lena strain viral load in the lung. Forty-two DPC, the histological score, the levels of expression of IL6, and of chemokine CCL20 were positively correlated (Figure 6B). This group of descriptors was negatively correlated with the level of expression of the CCL28 transcripts. The level of expression of CCL28 transcripts was positively correlated with the level of CXCL6 and

CXCR4 transcripts. A third group of positively correlated parameters included the level of expression of transcripts of CXC chemokine receptors 1-6, CCR10 and CCR3.

\section{Discussion}

In a previous study aimed at assessing and comparing the immune protection conferred by a Western European PRRSV strain (genotype 1.1) and genotypes 1 and 2 commercial MLV (MLV1 \& MLV2) vaccines against challenge with the virulent Lena strain, it was 
observed that the level of Lena viremia and clinical signs were reduced in all the immunized groups (Renson et al., 2017a). However, compared to vaccine strains, a slightly higher level of protection following immunization with Finistere strain was observed and attributed to a better cellular immune response. Thus, this previous study showed that cross-protection upon challenge with PRRSV Lena strain was possible with two vaccine strains (genotypes 1 and 2, respectively) and one circulating wild-type strain (Finistere) and that the protection was not related with the level of genetic similarity (Renson et al., 2017a). To reach these conclusions the previous study focused on clinical and zootechnical parameters, blood viral load, systemic humoral and cellular responses. However, it did not take into account the lung immune response even though in the first steps of infection PRRSV multiplies mostly in pulmonary macrophages. Thus, we performed this complementary investigation.

In this study, microscopic pulmonary lesions were observed in all groups of animals and histological scores were significantly higher in all infected groups both 10 and 42 DPC than in non-infected. This observation is not surprising considering that, 10 DPC, both blood and lung viral loads remained high in most of the groups except to some extent in Fini and that fever was mostly detected in NI and MLV2 where lesions were well identified (Renson et al., 2017a). Moreover, it is well-known that infections with virulent type 1 subtype 3 Lena strain result in more severe diseases than with other type 1 (Lelystad, Finistere or Belgium A for instance) strains (Renson et al., 2017b; Rose et al., 2015; Weesendorp et al., 2013). Regarding viral loads in the lung, results were similar to what was reported previously with blood viral loads (Renson et al., 2017a) and the lung viral load in the Fini group was significantly lower than in other groups 10 DPC. As previously suggested, the higher protection conferred by Finistere strain immunization compared to other immunization groups (MLV1 and MLV2) could be explained by a better cellular response as deduced from PRRSV-specific IFN $\gamma$ response detected by ELISPOT. This observation could also be linked 
to the attenuation of vaccine strains versus non-attenuated wild type Finistere strain and/or

route of administration (intranasal versus intramuscular) (Wu et al., 1997). Surprisingly, most severe lesions 10 DPC were observed in pigs immunized with MLV1 (70.2 $\pm 9.8 \%)$ and to a lower extent MLV2 (63 $\pm 9 \%)$ and foci of necrotic cells admixed with degenerated neutrophils were scattered in the lung parenchyma of the pigs from these groups. However, as previously reported, clinical signs such as rectal temperatures were already reduced 10 DPC in the MLV1 group and 11 DPC in the MLV2 group (Renson et al., 2017a) showing the protective effect of immunization with the two vaccines.

Because of the presence of foci of necrotic cells and degenerated neutrophils in the lung tissues of the MLV1 and MLV2 groups, we then assessed the expression of some transcripts related to inflammation (IL6 and TNF $\alpha$ ) and coding for some chemokines mostly involved in neutrophil recruitment (Kulkarni et al., 2017; Zlotnik and Yoshie, 2012). transcripts of CXCR1, receptor of CXCL8). To further verify our hypothesis, we looked at the specific role of the selected chemokines and their receptors. CXCL6, also known as 342 granulocyte chemotactic protein 2 (GCP-2), is produced by macrophages, epithelial and 343 mesenchymal cells during inflammation, is chemoattractant for neutrophilic granulocytes 344 (Proost et al., 1993; Zlotnik and Yoshie, 2012), has antimicrobial properties (Linge et al., 345 2008), and interacts with two receptors: CXCR1 and CXCR2 (Wuyts et al., 1997). 346 IL8/CXCL8, a CXC chemokine known as neutrophil chemotactic factor, is produced by 347 epithelial cells and macrophages and interacts with CXCR1 and CXCR2 (Harada et al., 1994; 
IUIS/WHO Subcommittee on Chemokine Nomenclature, 2003), which are expressed by eosinophils (Petering et al., 1999), neutrophils (Zlotnik and Yoshie, 2012), mast cells (Lippert et al., 1998), and some macrophages (Williams et al., 2000). CCL20, also known as Macrophage Inflammatory Protein-3 (MIP3A), belongs to the CC chemokine family and is strongly chemotactic for lymphocytes while it weakly attracts neutrophils (Hieshima et al., 1997). Thus, our qPCR data support more pronounced inflammatory processes in the MLV1 and MLV2 groups 10 DPC than in the Fini group confirming histo-pathological analyses. We then looked at various chemokine receptor transcripts, especially the ones involved in neutrophil recruitment, to see if chemokine transcript expression had visible consequences on receptor transcript expression. For that purpose, RT-qPCR assays targeting all the CXC chemokine receptors were developed for the pig species. In most cases, no significant differences but trends were observed between groups 42 DPC, probably because of a transient overexpression of receptor transcripts. For instance, it has been shown in mice that $\operatorname{IgA}$ antibody-secreting cells express high levels of the receptor CCR9 in lymphoid tissues associated with the gut but down-regulate the expression of the receptor once located in the lamina propria (Pabst et al., 2004).

To determine which variables were associated together, we carried out principal component analyses 10 and 42 DPC. Ten DPC, chemokine and CXCR1 variables were all positively correlated probably because the lung was facing Lena assaults and recruited inflammatory cells, particularly in MLV groups. Variables describing other chemokine receptors were all positively correlated together and negatively correlated to Lena lung viral load, illustrating most probably the importance of establishing the cellular arm of the immune response for Lena control. Indeed, CXCR3, CXCR4, CXCR5, CXCR6, and CCR10 are all involved in lymphocyte trafficking (Bonini and Steiner, 1997; Dobner et al., 1992; Groom and Luster, 2011; Loetscher et al., 1997; Moriuchi et al., 1997; Qin et al., 1998; Zlotnik and 
373 Yoshie, 2012). Moreover, the variables describing all these chemokines receptors were

374 positively correlated to Jung score 10 DPC. Forty-two DPC, the situation was different. This

375 is not surprising when we consider that the lung is recovering from PRRSV infection after the

376 clearance of most of the virus particles. At this time, the lesion score and the levels of

377 expression of IL6, IL8, and CCL20 transcripts were all positively correlated while they were

378 negatively correlated with the levels of expression of CCL28, CXCL6, and CXCR4

379 transcripts. Similarly, according to what was observed 10 DPC, other chemokine receptor

380 variables were all positively correlated. Thus, it appears that the picture is less clear long after

381 challenge than immediately after it. However, a positive correlation between major

382 inflammation actors such as IL6 and IL8/CXCL8 and the lesion score can still be observed.

383 Lena strain induces a stronger inflammatory response than Western European PRRSV strains

384 (Weesendorp et al., 2013) and even if it can contribute to a faster viral clearance it could take

385 a longer time for the tissue to fully recover from the induced lesions. CXCL6, CXCR4, and

386 CCL28 variables were negatively correlated to the first group of variables, which mostly

387 included inflammatory mediators and histological score. Interestingly, an alternative name for

388 CXCL6 is Alveolar Macrophage Chemotactic Factor 2 (Hunninghake et al., 1980; Proost et

389 al., 1993), CXCR4 is associated with lymphocytes and its signaling regulates the expression

390 of CD20 on B cells (Moriuchi et al., 1997; Pavlasova et al., 2016), and CCL28 is a strong

391 chemoattractant of antibody secreting cells (Berri et al., 2008; Feng et al., 2006; Kunkel et al.,

392 2003; Lazarus et al., 2003; Meurens et al., 2006; Wilson and Butcher, 2004). CCL28, also

393 known as mucosae-associated epithelial chemokine (MEC), has antimicrobial properties and

394 is expressed by lung mucosa where it drives homing of $\mathrm{T}$ and $\mathrm{B}$ lymphocytes expressing

395 CCR10 and eosinophils, macrophages, and T lymphocytes expressing CCR3 (Danilova et al.,

396 2015; Humbles et al., 2002; John et al., 2005; Kulkarni et al., 2017; Kunkel et al., 2003;

397 Mantovani et al., 2004; Zlotnik and Yoshie, 2012). Thus, we could hypothesize a role for 
these chemokines and chemokine receptor, all involved in macrophage and $\mathrm{T}$ cell trafficking, in the recovery process. Regarding potential links between biological variables and immunization groups, we did not observe any correlation, probably because of the low numbers of animals per groups and the relatively small differences between groups.

In conclusions, our study complements and further valorizes valuable samples collected from pigs immunized with two commercial vaccine strains and the Fini wild-type strain before Lena challenge. It shows a significant impact of the three types of immunizations on pulmonary tissue with the best protection against Lena challenge conferred by Fini strain, which induced less the expression of some inflammatory cytokines and chemokines. Furthermore, it gives insight into the interactions between vaccine and Fini strains of PRRSV and the lung upon Lena challenge. The study also provides a more global analysis of the immune lung response following PRRSV challenge giving clues for further studies aiming at better understanding the complex immuno-patho-physiology of PRRSV infections.

\section{Acknowledgements}

FM is supported by an establishment grant from the Région Pays de la Loire (RFI Food for tomorrow-Cap aliment). This lab work was carried out with the financial support of the regional programme "Food for Tomorrow / Cap Aliment; Research, Education and Innovation in Pays de la Loire“, which is supported by the French Region Pays de la Loire and the European Regional Development Fund (FEDER).We thank very much Coralie Chatellier and Amandine Bautru for their technical assistance during their training in the lab. Thanks also to Daniel Hogan for his helpful revision of the manuscript regarding English language. 
425 The authors declare that they have no conflict of interests.

426

427

428

429

430

431

432

433

434

435

436

437

438

439

440

441

442

443

444

445

446

447

\section{Conflict of interest statement}

\section{References} DNA Cell. Biol. 16, 1023-1030. https://doi.org/10.1038/mi.2014.46 https://doi.org/10.1016/j.vetimm.2011.08.002 https://doi.org/10.1186/1297-9716-45-42

Berri, M., Meurens, F., Lefevre, F., Chevaleyre, C., Zanello, G., Gerdts, V., Salmon, H., 2008. Molecular cloning and functional characterization of porcine CCL28: possible involvement in homing of $\operatorname{IgA}$ antibody secreting cells into the mammary gland. Mol. Immunol. 45, 271-277. https://doi.org/10.1016/j.molimm.2007.04.026

Bonini, J.A., Steiner, D.F., 1997. Molecular cloning and expression of a novel rat CCchemokine receptor (rCCR10rR) that binds MCP-1 and MIP-1beta with high affinity.

Danilova, E., Skrindo, I., Gran, E., Hales, B.J., Smith, W.A., Jahnsen, J., Johansen, F.E., Jahnsen, F.L., Baekkevold, E.S., 2015. A role for CCL28-CCR3 in T-cell homing to the human upper airway mucosa. Mucosal Immunol. 8, 107-14.

Delgado-Ortega, M., Melo, S., Meurens, F., 2011. Expression of SOCS1-7 and CIS mRNA in porcine tissues. Vet Immunol Immunopathol 144, 493-498.

Delgado-Ortega, M., Melo, S., Punyadarsaniya, D., Ramé, C., Olivier, M., Soubieux, D., Marc, D., Simon, G., Herrler, G., Berri, M., Dupont, J., Meurens, F., 2014. Innate immune response to a $\mathrm{H} 3 \mathrm{~N} 2$ subtype swine influenza virus in newborn porcine trachea cells, alveolar macrophages, and precision-cut lung slices. Vet. Res. 45, 42. 
Dobner, T., Wolf, I., Emrich, T., Lipp, M., 1992. Differentiation-specific expression of a novel G protein-coupled receptor from Burkitt's lymphoma. Eur. J. Immunol. 22, 27952799. https://doi.org/10.1002/eji.1830221107

Dobrescu, I., Levast, B., Lai, K., Delgado-Ortega, M., Walker, S., Banman, S., Townsend, H., Simon, G., Zhou, Y., Gerdts, V., Meurens, F., 2014. In vitro and ex vivo analyses of coinfections with swine influenza and porcine reproductive and respiratory syndrome viruses. Vet. Microbiol. 169, 18-32. https://doi.org/10.1016/j.vetmic.2013.11.037

Du, T., Nan, Y., Xiao, S., Zhao, Q., Zhou, E.-M., 2017. Antiviral Strategies against PRRSV Infection. Trends Microbiol. 25, 968-979. https://doi.org/10.1016/j.tim.2017.06.001

Feng, N., Jaimes, M.C., Lazarus, N.H., Monak, D., Zhang, C., Butcher, E.C., Greenberg, H.B., 2006. Redundant role of chemokines CCL25/TECK and CCL28/MEC in IgA+ plasmablast recruitment to the intestinal lamina propria after rotavirus infection. $\mathrm{J}$. Immunol. 176, 5749-5759.

Groom, J.R., Luster, A.D., 2011. CXCR3 in T cell function. Exp. Cell Res. 317, 620-631. https://doi.org/10.1016/j.yexcr.2010.12.017

Harada, A., Sekido, N., Akahoshi, T., Wada, T., Mukaida, N., Matsushima, K., 1994. Essential involvement of interleukin-8 (IL-8) in acute inflammation. J. Leukoc. Biol. 56, $559-64$.

Hieshima, K., Imai, T., Opdenakker, G., Van Damme, J., Kusuda, J., Tei, H., Sakaki, Y., Takatsuki, K., Miura, R., Yoshie, O., Nomiyama, H., 1997. Molecular cloning of a novel human CC chemokine liver and activation-regulated chemokine (LARC) expressed in liver. Chemotactic activity for lymphocytes and gene localization on chromosome 2. J. Biol. Chem. 272, 5846-53.

Humbles, A.A., Lu, B., Friend, D.S., Okinaga, S., Lora, J., Al-garawi, A., Martin, T.R., Gerard, N.P., Gerard, C., 2002. The murine CCR3 receptor regulates both the role of 
eosinophils and mast cells in allergen-induced airway inflammation and

474 hyperresponsiveness. Proc. Natl. Acad. Sci. 99, 1479-1484. $475 \quad$ https://doi.org/10.1073/pnas.261462598

476 Hunninghake, G.W., Gadek, J.E., Fales, H.M., Crystal, R.G., 1980. Human Alveolar 477 Macrophage-derived Chemotactic Factor for Neutrophils. J. Clin. Invest. 66, 473-483. 478 https://doi.org/10.1172/JCI109878

479 IUIS/WHO Subcommittee on Chemokine Nomenclature, 2003. Chemokine/chemokine $480 \quad$ receptor nomenclature. Cytokine 21, 48-9.

481 John, A.E., Thomas, M.S., Berlin, A.A., Lukacs, N.W., 2005. Temporal production of CCL28

482 corresponds to eosinophil accumulation and airway hyperreactivity in allergic airway 483 inflammation. Am. J. Pathol. 166, 345-53. https://doi.org/10.1016/S0002$4849440(10) 62258-4$

485 Joliffe, I., 2002. Principal component analysis, 2nd Editio. ed. Springer New York, New $486 \quad$ York, USA.

487 Jung, K., Alekseev, K.P., Zhang, X., Cheon, D.S., Vlasova, A.N., Saif, L.J., 2007. Altered 488 pathogenesis of porcine respiratory coronavirus in pigs due to immunosuppressive 489 effects of dexamethasone: implications for corticosteroid use in treatment of severe acute $490 \quad$ respiratory syndrome coronavirus. J. Virol. 81, 13681-13693.

491 Karniychuk, U.U., Saha, D., Vanhee, M., Geldhof, M., Cornillie, P., Caij, A.B., De Regge, N., 492 Nauwynck, H.J., 2012. Impact of a novel inactivated PRRS virus vaccine on virus 493 replication and virus-induced pathology in fetal implantation sites and fetuses upon $494 \quad$ challenge. $\quad$ Theriogenology $\quad 78, \quad 1527-37$. 495 https://doi.org/10.1016/j.theriogenology.2012.06.015

496 Keffaber, K.K., 1989. Reproductive failure of unknown etiology. Am. Assoc. Swine Pr. $497 \quad$ Newsl. 1, 1-9. 
Kulkarni, N., Pathak, M., Lal, G., 2017. Role of chemokine receptors and intestinal epithelial cells in the mucosal inflammation and tolerance. J. Leukoc. Biol. 101, 377-394. https://doi.org/10.1189/jlb.1RU0716-327R

Kunkel, E.J., Kim, C.H., Lazarus, N.H., Vierra, M.A., Soler, D., Bowman, E.P., Butcher, E.C., 2003. CCR10 expression is a common feature of circulating and mucosal epithelial tissue IgA Ab-secreting cells. J. Clin. Invest. 111, 1001-1010.

Lazarus, N.H., Kunkel, E.J., Johnston, B., Wilson, E., Youngman, K.R., Butcher, E.C., 2003. A common mucosal chemokine (mucosae-associated epithelial chemokine/CCL28) selectively attracts IgA plasmablasts. J. Immunol. 170, 3799-3805.

Linge, H.M., Collin, M., Nordenfelt, P., Morgelin, M., Malmsten, M., Egesten, A., 2008. The Human CXC Chemokine Granulocyte Chemotactic Protein 2 (GCP-2)/CXCL6 Possesses Membrane-Disrupting Properties and Is Antibacterial. Antimicrob. Agents Chemother. 52, 2599-2607. https://doi.org/10.1128/AAC.00028-08

Lippert, U., Artuc, M., Grützkau, A., Möller, A., Kenderessy-Szabo, A., Schadendorf, D., Norgauer, J., Hartmann, K., Schweitzer-Stenner, R., Zuberbier, T., Henz, B.M., KrügerKrasagakes, S., 1998. Expression and functional activity of the IL-8 receptor type CXCR1 and CXCR2 on human mast cells. J. Immunol. 161, 2600-8.

Loetscher, M., Amara, A., Oberlin, E., Brass, N., Legler, D., Loetscher, P., D’Apuzzo, M., Meese, E., Rousset, D., Virelizier, J.L., Baggiolini, M., Arenzana-Seisdedos, F., Moser, B., 1997. TYMSTR, a putative chemokine receptor selectively expressed in activated T cells, exhibits HIV-1 coreceptor function. Curr. Biol. 7, 652-60.

Lunney, J.K., Fang, Y., Ladinig, A., Chen, N., Li, Y., Rowland, B., Renukaradhya, G.J., 2016. Porcine Reproductive and Respiratory Syndrome Virus (PRRSV): Pathogenesis and Interaction with the Immune System. Annu. Rev. Anim. Biosci. 4, 129-154. https://doi.org/10.1146/annurev-animal-022114-111025 
Mantovani, A., Sica, A., Sozzani, S., Allavena, P., Vecchi, A., Locati, M., 2004. The chemokine system in diverse forms of macrophage activation and polarization. Trends Immunol. 25, 677-686. https://doi.org/10.1016/j.it.2004.09.015

Meurens, F., Berri, M., Auray, G., Melo, S., Levast, B., Virlogeux-Payant, I., Chevaleyre, C., Gerdts, V., Salmon, H., 2009. Early immune response following Salmonella enterica subspecies enterica serovar Typhimurium infection in porcine jejunal gut loops. Vet. Res. 40. https://doi.org/10.1051/vetres:2008043

Meurens, F., Berri, M., Siggers, R.H.H., Willing, B.P.P., Salmon, H., Van Kessel, A.G.G., Gerdts, V., 2007. Commensal bacteria and expression of two major intestinal chemokines, TECK/CCL25 and MEC/CCL28, and their receptors. PLoS One 2, e677. https://doi.org/10.1371/journal.pone.0000677

Meurens, F., Berri, M., Whale, J., Dybvig, T., Strom, S., Thompson, D., Brownlie, R., Townsend, H.G.G., Salmon, H., Gerdts, V., 2006. Expression of TECK/CCL25 and MEC/CCL28 chemokines and their respective receptors CCR9 and CCR10 in porcine mucosal tissues. $\quad$ Vet. Immunol. Immunopathol. 113. https://doi.org/10.1016/j.vetimm.2006.05.014

Moriuchi, M., Moriuchi, H., Turner, W., Fauci, A.S., 1997. Cloning and analysis of the promoter region of CXCR4, a coreceptor for HIV-1 entry. J. Immunol. 159, 4322-9.

Nygard, A.B., Jorgensen, C.B., Cirera, S., Fredholm, M., 2007. Selection of reference genes for gene expression studies in pig tissues using SYBR green qPCR. BMC Mol. Biol. 8, 67.

Pabst, O., Ohl, L., Wendland, M., Wurbel, M.A., Kremmer, E., Malissen, B., Forster, R., 2004. Chemokine receptor CCR9 contributes to the localization of plasma cells to the small intestine. J. Exp. Med. 199, 411-416.

Pavlasova, G., Borsky, M., Seda, V., Cerna, K., Osickova, J., Doubek, M., Mayer, J., 
Calogero, R., Trbusek, M., Pospisilova, S., Davids, M.S., Kipps, T.J., Brown, J.R., Mraz, M., 2016. Ibrutinib inhibits CD20 upregulation on CLL B cells mediated by the CXCR4/SDF-1 axis. Blood 128, 1609-1613. https://doi.org/10.1182/blood-2016-04709519

Petering, H., Götze, O., Kimmig, D., Smolarski, R., Kapp, A., Elsner, J., 1999. The biologic role of interleukin-8: functional analysis and expression of CXCR1 and CXCR2 on human eosinophils. Blood 93, 694-702.

Proost, P., Wuyts, A., Conings, R., Lenaerts, J.P., Billiau, A., Opdenakker, G., Van Damme, J., 1993. Human and bovine granulocyte chemotactic protein-2: complete amino acid sequence and functional characterization as chemokines. Biochemistry 32, 10170-7.

Qin, S., Rottman, J.B., Myers, P., Kassam, N., Weinblatt, M., Loetscher, M., Koch, A.E., Moser, B., Mackay, C.R., 1998. The chemokine receptors CXCR3 and CCR5 mark subsets of $\mathrm{T}$ cells associated with certain inflammatory reactions. J. Clin. Invest. 101, 746-54. https://doi.org/10.1172/JCI1422

Renson, P., Fablet, C., Le Dimna, M., Mahé, S., Touzain, F., Blanchard, Y., Paboeuf, F., Rose, N., Bourry, O., 2017a. Preparation for emergence of an Eastern European porcine reproductive and respiratory syndrome virus (PRRSV) strain in Western Europe: Immunization with modified live virus vaccines or a field strain confers partial protection. Vet. Microbiol. 204, 133-140. https://doi.org/10.1016/j.vetmic.2017.04.021

Renson, P., Rose, N., Le Dimna, M., Mahé, S., Keranflec'h, A., Paboeuf, F., Belloc, C., Le Potier, M.-F., Bourry, O., 2017b. Dynamic changes in bronchoalveolar macrophages and cytokines during infection of pigs with a highly or low pathogenic genotype 1 PRRSV strain. Vet. Res. 48, 15. https://doi.org/10.1186/s13567-017-0420-y

Riva, M., Manzoni, M., Isimbaldi, G., Cesana, G., Pagni, F., 2014. Histochemistry: historical development and current use in pathology. Biotech. Histochem. 89, 81-90. 
574 Rose, N., Renson, P., Andraud, M., Paboeuf, F., Le Potier, M.F., Bourry, O., 2015. Porcine

575 reproductive and respiratory syndrome virus (PRRSv) modified-live vaccine reduces

576 virus transmission in experimental conditions. Vaccine 33, 2493-9.

577 https://doi.org/10.1016/j.vaccine.2015.03.040

578 Snijder, E.J., Kikkert, M., Fang, Y., 2013. Arterivirus molecular biology and pathogenesis. J.

579 Gen. Virol. 94, 2141-2163. https://doi.org/10.1099/vir.0.056341-0

580 Vandesompele, J., De Preter, K., Pattyn, F., Poppe, B., Van Roy, N., De Paepe, A., Speleman,

581 F., 2002. Accurate normalization of real-time quantitative RT-PCR data by geometric

582 averaging of multiple internal control genes. Genome Biol 3, RESEARCH0034.

583 Weesendorp, E., Morgan, S., Stockhofe-Zurwieden, N., Graaf, D.J.P.-D., Graham, S.P.,

584 Rebel, J.M.J., 2013. Comparative analysis of immune responses following experimental

585 infection of pigs with European porcine reproductive and respiratory syndrome virus

586 strains of differing virulence. Vet. Microbiol. 163, 1-12.

$587 \quad$ https://doi.org/10.1016/j.vetmic.2012.09.013

588 Wensvoort, G., Terpstra, C., Pol, J.M., ter Laak, E.A., Bloemraad, M., de Kluyver, E.P.,

589 Kragten, C., van Buiten, L., den Besten, A., Wagenaar, F., al., et, 1991. Mystery swine

590 disease in The Netherlands: the isolation of Lelystad virus. Vet. Q 13, 121-130.

591 Williams, E.J., Haque, S., Banks, C., Johnson, P., Sarsfield, P., Sheron, N., 2000. Distribution

592 of the interleukin-8 receptors, CXCR1 and CXCR2, in inflamed gut tissue. J. Pathol.

$593 \quad$ 192, 533-539. https://doi.org/10.1002/1096-9896(2000)9999:9999<::AID-

$594 \quad$ PATH732>3.0.CO;2-X

595 Wilson, E., Butcher, E.C., 2004. CCL28 controls immunoglobulin (Ig)A plasma cell 596 accumulation in the lactating mammary gland and $\operatorname{IgA}$ antibody transfer to the neonate.

597 J. Exp. Med. 200, 805-809. 
609

610

611

612

613

614

615

616

617

618

619

620

621

622

Wu, H.Y., Nguyen, H.H., Russell, M.W., 1997. Nasal lymphoid tissue (NALT) as a mucosal immune inductive site. Scand. J. Immunol. 46, 506-513.

Wuyts, A., Van Osselaer, N., Haelens, A., Samson, I., Herdewijn, P., Ben-Baruch, A., Oppenheim, J.J., Proost, P., Van Damme, J., 1997. Characterization of synthetic human granulocyte chemotactic protein 2: usage of chemokine receptors CXCR1 and CXCR2 and in vivo inflammatory properties. Biochemistry 36, 2716-23. https://doi.org/10.1021/bi961999z

Zlotnik, A., Yoshie, O., 2012. The Chemokine Superfamily Revisited. Immunity 36, 705-716. https://doi.org/10.1016/J.IMMUNI.2012.05.008

\section{Figure captions}

Figure 1: Viral replication - Relative quantification of viral load in lung tissue 10 or 42 days post-challenge (DPC). In each group $n=3$ to 5 (median is indicated by the small bar). Dot plots within each graph with no common superscripts are significantly different $(p<0.05)$. MLV1 group: pigs immunized with the MLV1 vaccine; MLV2 group: pigs immunized with the MLV2 vaccine; Fini group: pigs immunized with the Finistere strain of PRRSV; NI group: non-immunized pigs.

Figure 2: (A) Lung histopathology - Representative pictures of the histopathological lesions observed in control, MLV1, MLV2 or Finistere PRRSV (Fini) strain-inoculated pigs before Lena strain challenge or Lena strain alone (NI), 10 (upper panel) and 42 (lower panel) days post-challenge (DPC). Compared to control animals, lungs of PRRSV inoculated/immunized and challenged animals displayed severe bronchopneumonia characterized by alveolar wall thickening by inflammatory cells, presence of necrotic and cellular debris in respiratory 
623

624

625

626

627

628

629

630

631

632

633

634

635

636

637

638

639

640

641

642

643

644

645

646

647

airways ((open) arrowhead) and peri-bronchiolar and peri-vascular cuffing by inflammatory cells (arrow). Note, 42 DPC, hyperplasia of Bronchi-Associated Lymphoid Tissues (*). Hematoxylin-eosin-saffron stain, bar $=100 \mu \mathrm{m}$. (B) High magnification of lung parenchyma. Compared to control animals, all Lena-infected animals displayed thickening of alveolar septa by some inflammatory cells, mainly mononucleated ones (black arrowhead). 10 days post-challenge (DPC), in MLV1 and MLV2 groups, some neutrophils (arrow) were regularly observed around small foci of necrotic debris accumulation (open arrowhead). Meanwhile, these foci and neutrophils were almost absent in Fini and NI animals. Hematoxylin-eosin-saffron stain, bar $=10 \mu \mathrm{m}$.

Figure 3: Composite scores in the different groups 10 and 42 DPC. In each group $n=3$ to 5 (median is indicated by the small bar). Dot plots within each graph with no common superscripts are significantly different $(p<0.05)$. MLV1 group: pigs immunized with the MLV1 vaccine; MLV2 group: pigs immunized with the MLV2 vaccine; Fini group: pigs immunized with the Finistere strain of PRRSV; NI group: non-immunized pigs.

Figure 4: (A) Innate immune response - Relative expression of transcripts in lung tissues 10 or 42 days post Lena challenge (DPC). (B) CCL28 chemokine and its receptors - Relative expression of transcripts in lung tissues 10 or 42 days post-challenge (DPC). In each group $\mathrm{n}=3$ to 5 (median is indicated by the small bar). Dot plots within each graph with no common superscripts are significantly different $(p<0.05)$. MLV1 group: pigs immunized with the MLV1 vaccine; MLV2 group: pigs immunized with the MLV2 vaccine; Fini group: pigs immunized with the Finistere strain of PRRSV; NI group: non-immunized pigs.

Figure 5: CXCR chemokines - Relative expression of transcripts in lung tissues 10 or 42 
days post-challenge (DPC). In each group $n=3$ to 5 (median is indicated by the small bar). Dot plots within each graph with no common superscripts are significantly different $(p<0.05)$. MLV1 group: pigs immunized with the MLV1 vaccine; MLV2 group: pigs immunized with the MLV2 vaccine; Fini group: pigs immunized with the Finistere strain of PRRSV; NI group: non-immunized pigs.

Figure 6: Results of the principal component analysis describing, 10 days (A) and 42 days (B) after a Lena strain challenge, the associations between viral, histologic and immune descriptors of pigs, pre-immunized or not, before the Lena strain challenge (16 pigs in A and 18 in B) - IL6_10: Level of expression of the IL6; IL8_10: Level of expression of the chemokine ligand 8; CCL20_10: Level of expression of the chemokine ligand 20; CXCL6_10: Level of expression of the chemokine ligand 6; CXCR1_10: Level of expression of transcript of the chemokine receptor 1; CXCR2_10: Level of expression of transcript of the chemokine receptor 2; CXCR3_10: Level of expression of transcript of the chemokine receptor 3; CXCR4_10: Level of expression of transcript of the chemokine receptor4; CXCR5_10: Level of expression of transcript of the chemokine receptor 5; CXCR6_10: Level of expression of transcript of the chemokine receptor 6; CCL28_10: CXCL6_10: Level of expression of the chemokine ligand 28; CCR3_10: Level of expression of transcript of the chemokine receptor 3; CCR10_10: Level of expression of transcript of the chemokine receptor 10; RTPCR_Lena_10: Viral Lena strain load in the lung ; IL6_42: Level of expression of the IL6; IL8_42: Level of expression of the chemokine ligand 8; CCL20_42: Level of expression of the chemokine ligand 20; CXCL6_42: Level of expression of the chemokine ligand 6; CXCR1_42: Level of expression of transcript of the chemokine receptor 1; CXCR2_42: Level of expression of transcript of the chemokine receptor 2; CXCR3_42: Level of expression of transcript of the chemokine receptor 3; CXCR4_42: Level of 
673 expression of transcript of the chemokine receptor4; CXCR5_42: Level of expression of 674 transcript of the chemokine receptor 5; CXCR6_42: Level of expression of transcript of the 675 chemokine receptor 6; CCL28_42: CXCL6_42: Level of expression of the chemokine ligand 676 28; CCR3_42: Level of expression of transcript of the chemokine receptor 3; CCR10_42:

677 Level of expression of transcript of the chemokine receptor 10 ; Jung score: Histologic Jung 678 score. 


\section{PRRSV replication}

PRRSV universal primers

Cq: 19-33
Lena PRRSV primers \& probe

Cq: 17-33

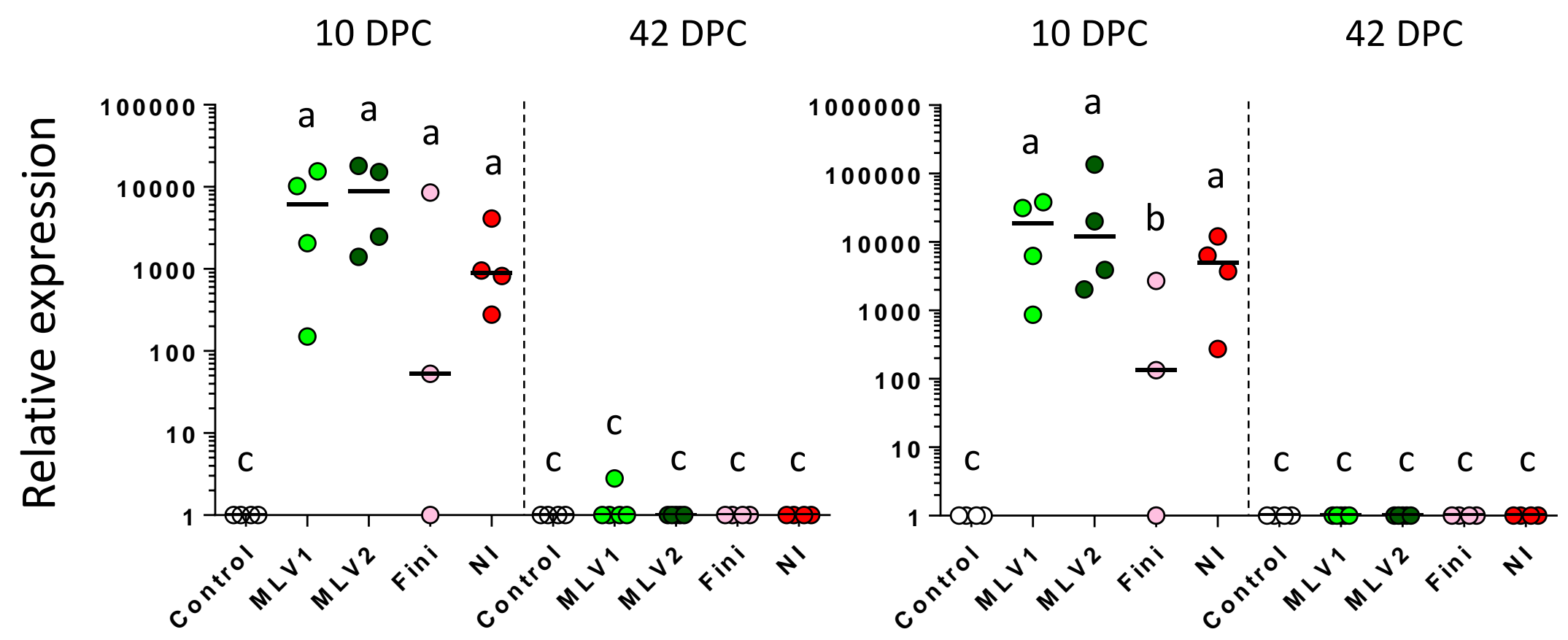

Figure 1 

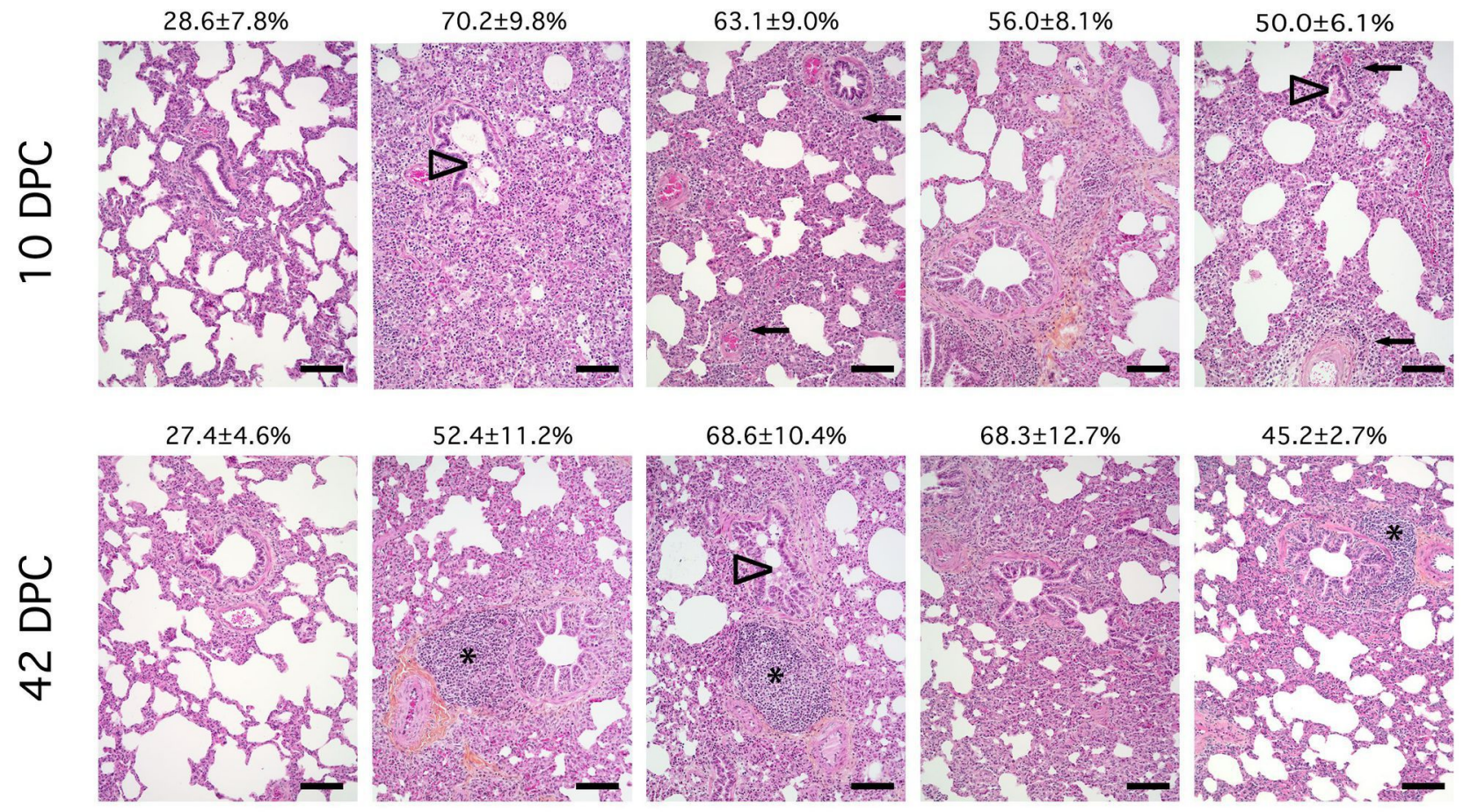

B

Control

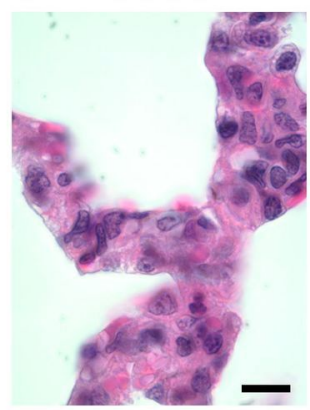

MLV1

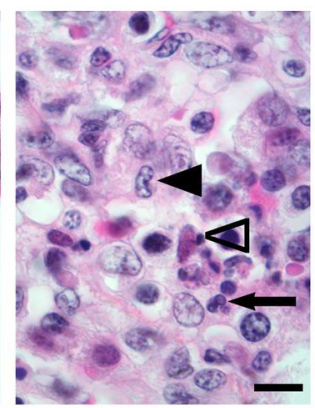

MLV2

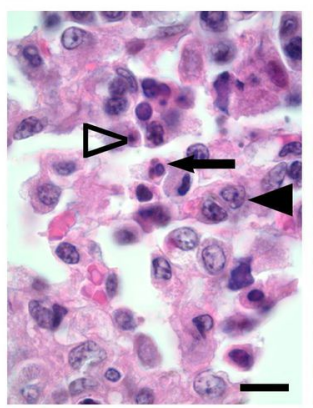

Fini

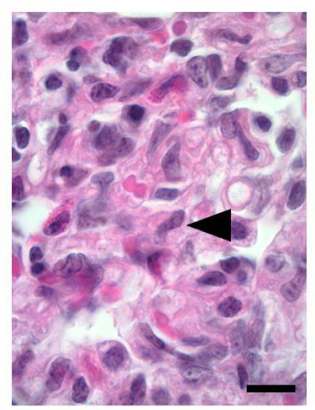

$\mathrm{NI}$

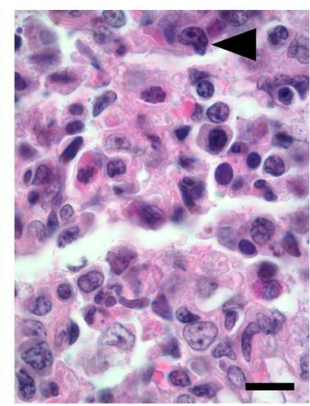




\section{$10 \mathrm{DPC} \quad 42 \mathrm{DPC}$}

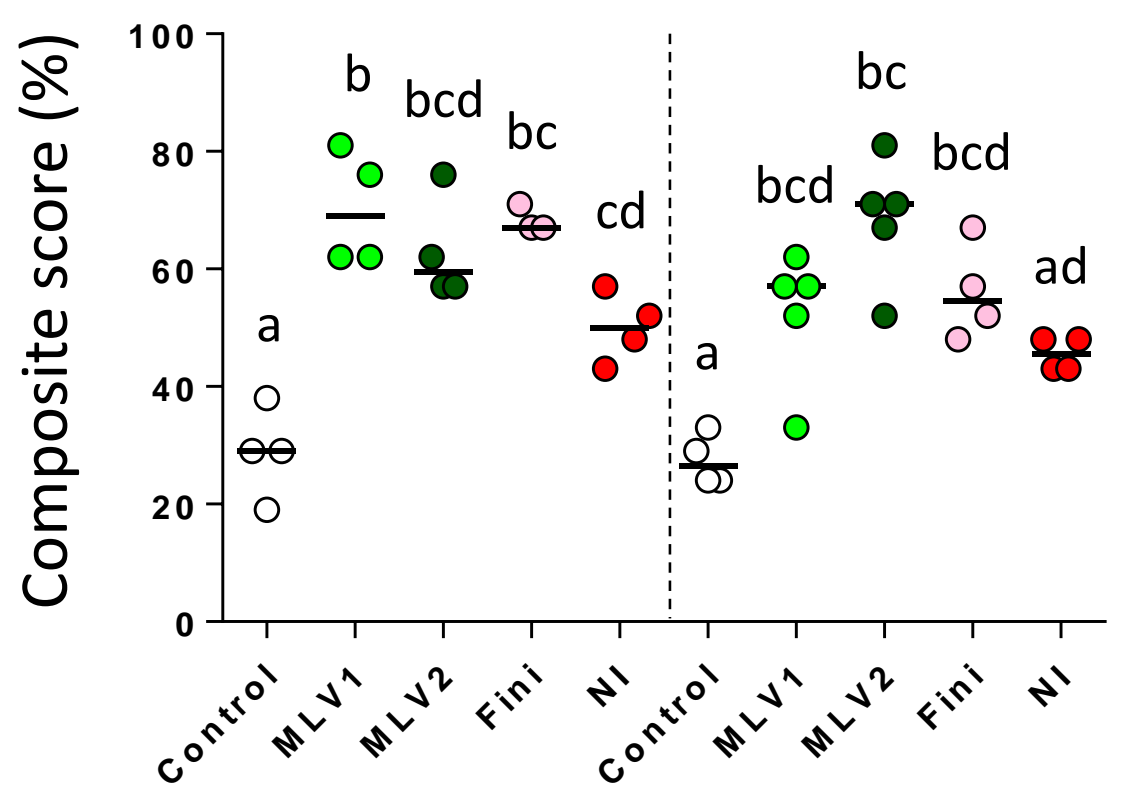

Figure 3 
IL6

Cq: $25-29$

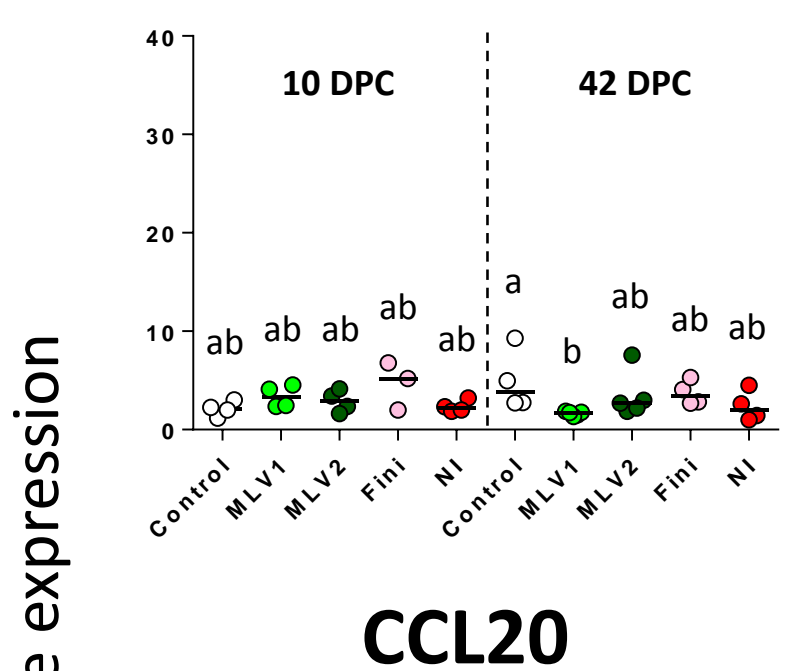

$\sum_{ \pm}^{0}$

$\frac{1}{0}$

\section{CCL28}

Cq: $23-28$

Cq: $23-30$

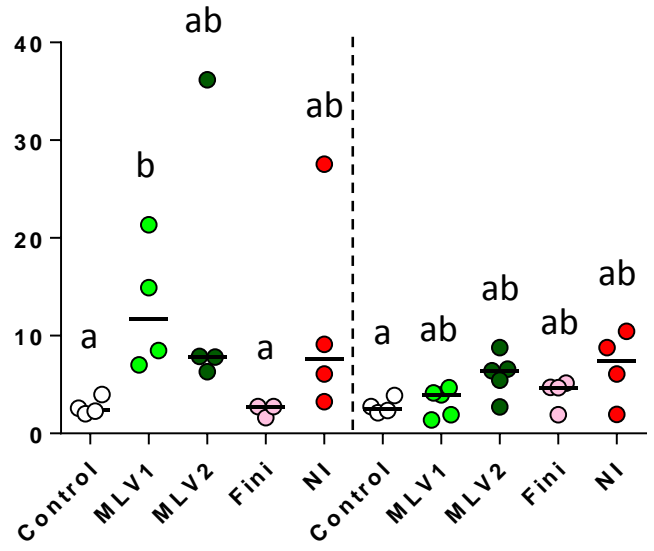

CXCL6

Cq: 25-32
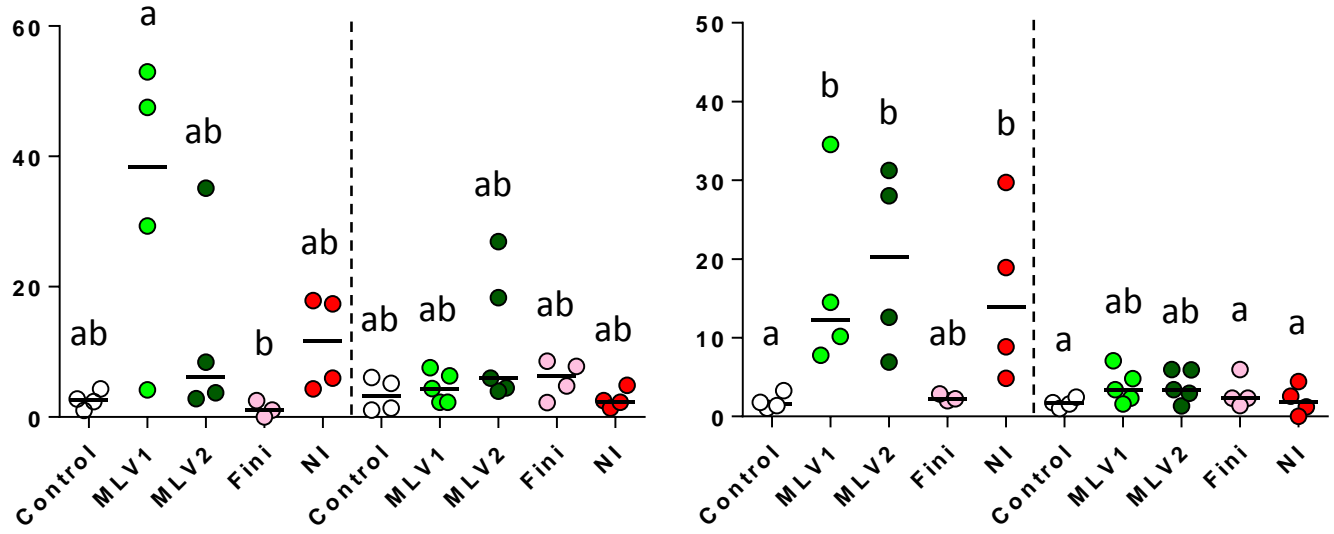

\section{CCR3}

Cq: $22-26$
CCR10

Cq: 26-34

$\frac{5}{0}$

42 DPC
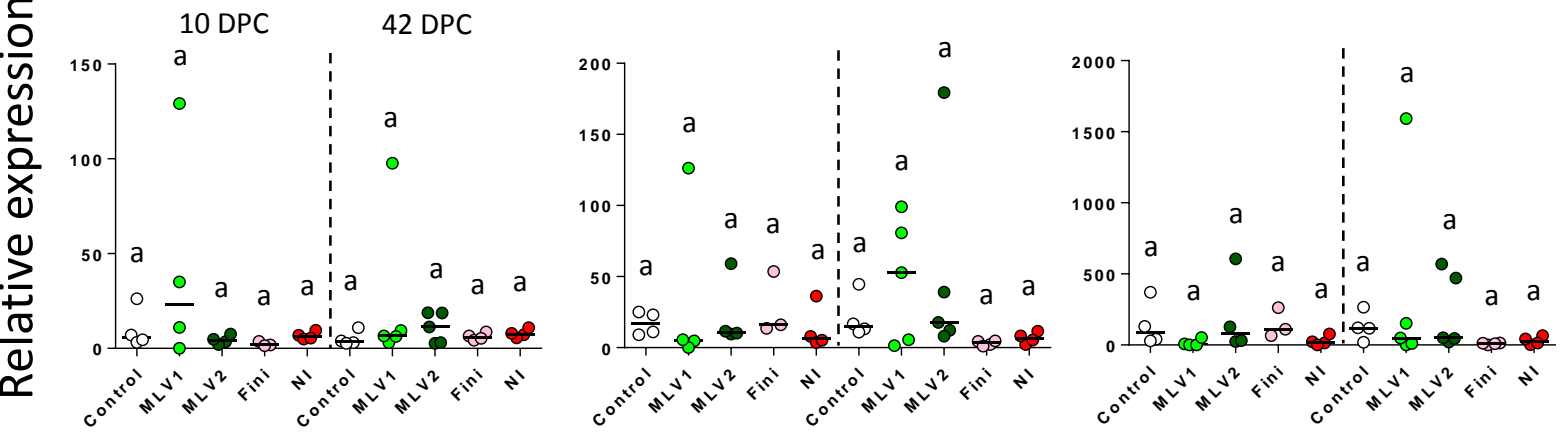

Figure 4 
CXCR1

Cq: 29-34
CXCR2

Cq: 23-31
CXCR3

Cq: 23-28

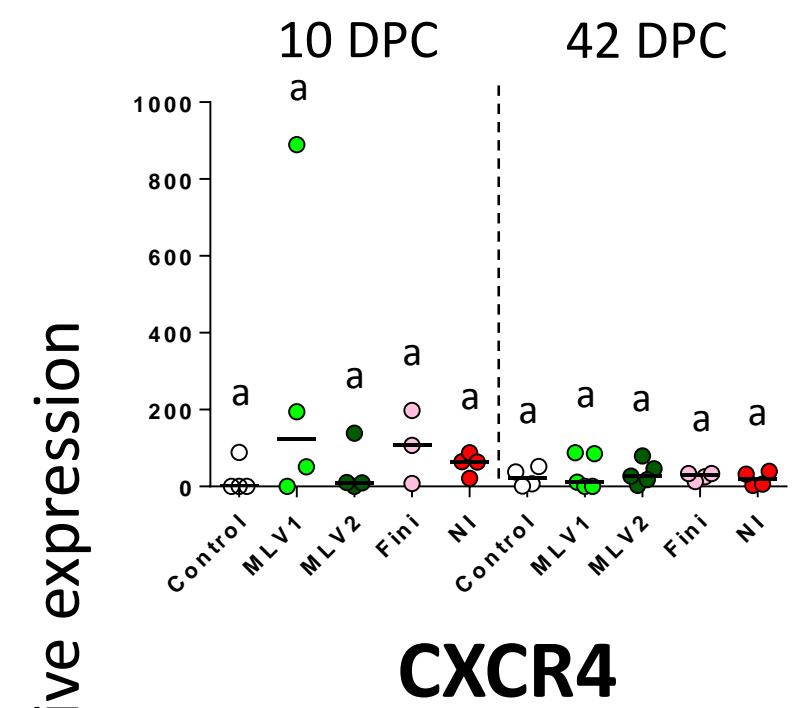

Cq: 21-27

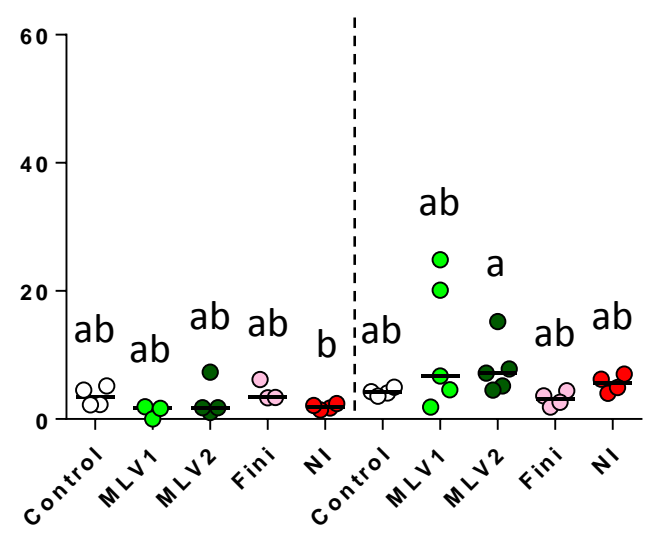

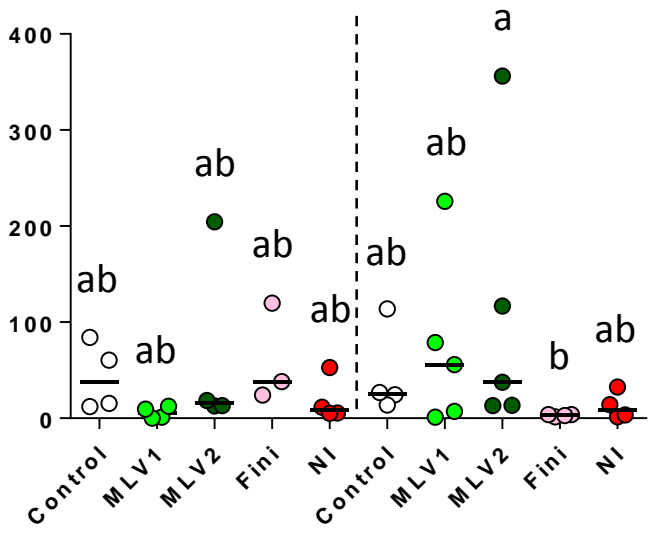

CXCR5

Cq: 22-27

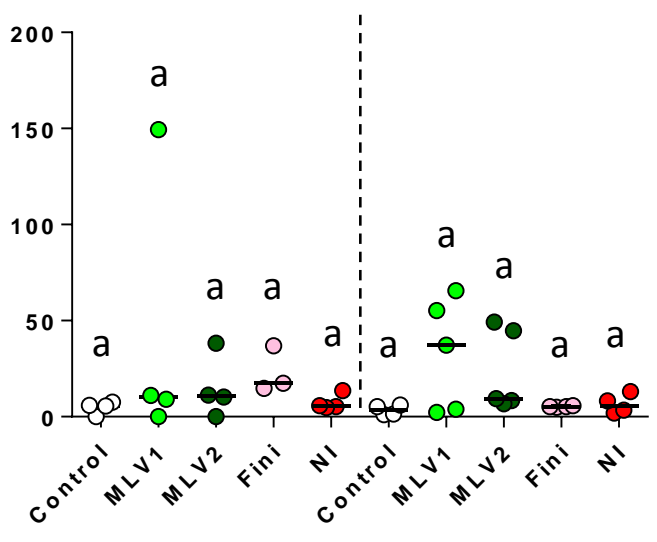

CXCR6

Cq: 24-29

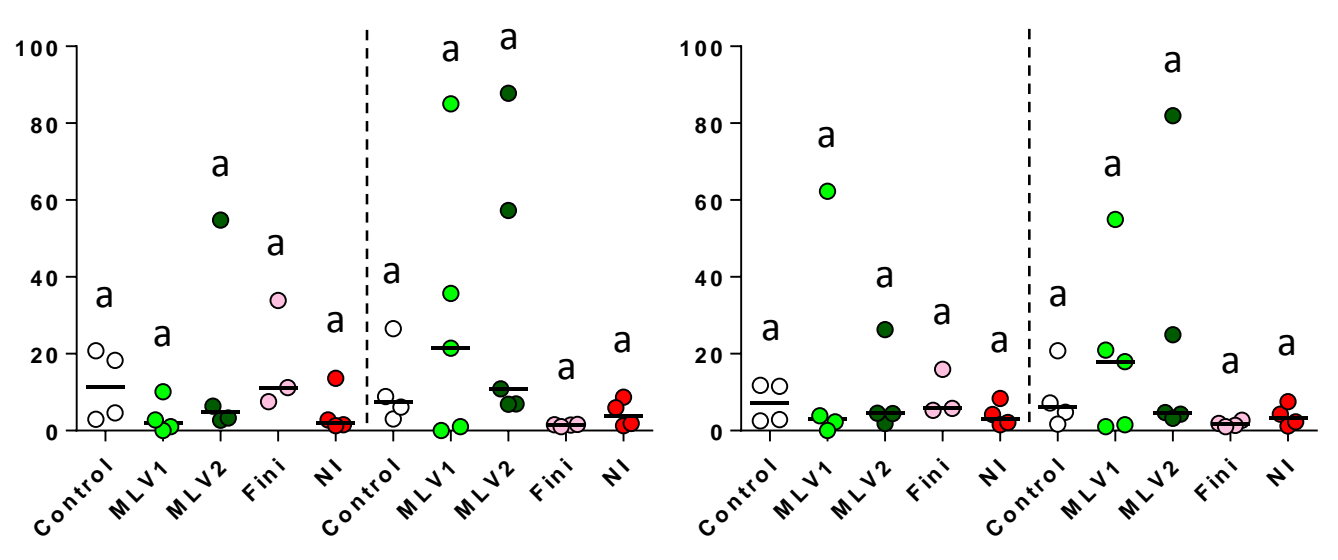

Figure 5 

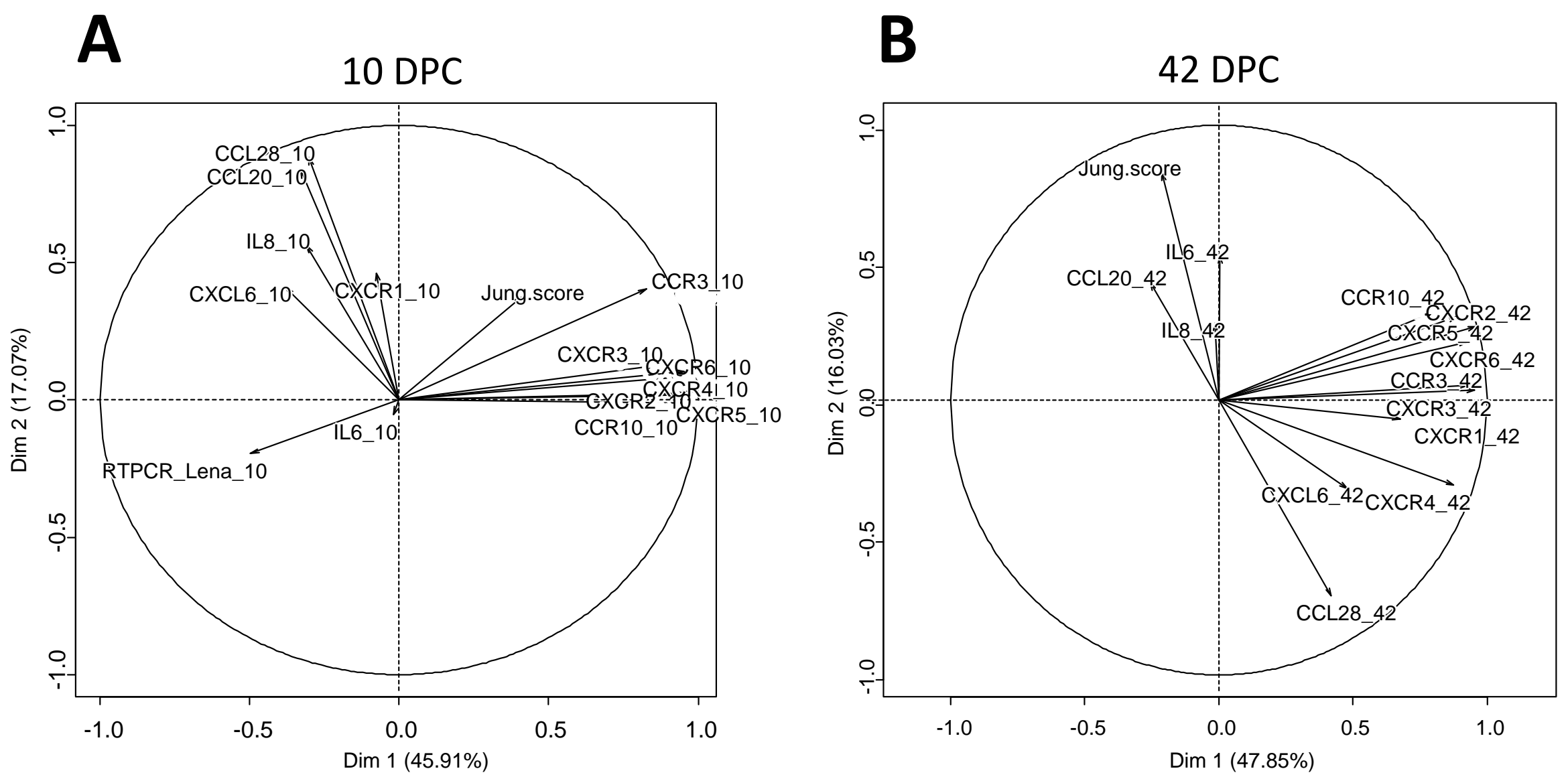

Figure 6 
Table I: Experimental design

\begin{tabular}{lcccc}
\hline Groups & Immunization (D -27) & Challenge (D0) & $\begin{array}{l}\text { Number of pigs } \\
\text { necropsied 10 DPC }\end{array}$ & $\begin{array}{l}\text { Number of pigs } \\
\text { necropsied 42 DPC }\end{array}$ \\
\hline Control & / & / & 4 & 4 \\
$\begin{array}{l}\text { MLV1 } \\
\text { Genotype 1.1 }\end{array}$ & Ingelvac PRRSVFLEX EU, IM & Lena, IN & 4 & 5 \\
$\begin{array}{l}\text { MLV2 } \\
\text { Genotype 2 }\end{array}$ & Ingelvac PRRSV MLV, IM & Lena, IN & 4 & 5 \\
$\begin{array}{l}\text { Finistere (Fini) } \\
\text { Genotype 1.1 }\end{array}$ & Finistere strain, IN & Lena, IN & 3 & 4 \\
$\begin{array}{l}\text { Lena (NI) } \\
\text { Genotype 1.3 }\end{array}$ & / & Lena, IN & 4 & 4 \\
\hline
\end{tabular}

IN: intranasal ; IM: intramuscular ; DPC: day post challenge; NI: non-immunized 
Table II: List of primers used in the study

Primer abbreviation and full

name

Primer sequences: sense $(S) \&$ anti-sense (AS)

1) PRRSV

PRRSV Universal

PRRSV Lena

\section{2) REFERENCE GENES}

B2MI
Beta-2-microgobulin
HPRT1
Hypoxanthine phosphoribosyltransferase 1
RPL19
Ribosomal protein L19

\section{3) INTERFERON AND CYTOKINES} IFN $\gamma$

Interferon gamma (Type II)

$$
\text { IL6 }
$$

Interleukin 6

IL10

Interleukin 10

TNF $\alpha$

Tumor Necrosis Factor alpha

\section{4) CHEMOKINES}

CCL20

Chemokine (C-C motif) ligand 20 CCL28

Chemokine (C-C motif) ligand 28 CXCL6

Chemokine (C-X-C motif) ligand 6

CXCL8/IL8

Chemokine (C-X-C motif) ligand 8

5) CHEMOKINE RECEPTORS

CCR3

Chemokine (CC motif) receptor 3 CCR6

Chemokine (CC motif) receptor 6 CCR10

Chemokine (CC motif) receptor 10 CXCR1

Chemokine (CXC motif) receptor 1 CXCR2

Chemokine (CXC motif) receptor 2 CXCR3

Chemokine (CXC motif) receptor 3 CXCR4

Chemokine (CXC motif) receptor 4 CXCR5

Chemokine (CXC motif) receptor 5 CXCR6

Chemokine (CXC motif) receptor 6 CXCR7

Chemokine (CXC motif) receptor 7
(S) ATGGCCAGCCAGTCAATCAG (AS) GGAACGTTCAGTTCCGGTGA

(S) AGAACCAGCGCCAATTCAGA (AS) TCTTTTTCGCCTGTCCTCCC (P) (6FAM)AAACACAGCTCCAATGGGGAATGGC-(TAM)

(S) CAAGATAGTTAAGTGGGATCGAGAC (AS) TGGTAACATCAATACGATTTCTGA

(S) GGACTTGAATCATGTTTGTG

(AS) CAGATGTTTCCAAACTCAAC

(S) AACTCCCGTCAGCAGATCC

(AS) AGTACCCTTCCGCTTACCG

(S) GCTCTGGGAAACTGAATGAC (AS) TCTCTGGCCTTGGAACATAG

(S) ATCAGGAGACCTGCTTGATG

(AS) TGGTGGCTTTGTCTGGATTC

(S) ACCAGATGGGCGACTTGTTG

(AS) TCTCTGCCTTCGGCATTACG

(S) CCAATGGCAGAGTGGGTATG

(AS) TGAAGAGGACCTGGGAGTAG

(S) GCTCCTGGCTGCTTTGATGTC

(AS) CATTGGCGAGCTGCTGTGTG

(S) GCTGCTGCACTGAGGTTTC

(AS) TGAGGGCTGACACAGATTC

(S) TTGCCAGCGCTAGTCCTATC

(AS) TTCAGGGTGGCTATCACTTC

(S) TCCTGCTTTCTGCAGCTCTC

(AS) GGGTGGAAAGGTGTGGAATG

(S) TCCTATTCACGCTGCCATTC

(AS) TGCAGACCACATCTCCAAAC

(S) GGCAGAAGTTCCGGAGCTAC

(AS) TGGTGAAGGAGGACGGATTG

(S) TCCTGCTTTCTGCAGCTCTC

(AS) GGGTGGAAAGGTGTGGAATG

(S) ATGGCTGGTGATTCAGATCG

(AS) ACCAGGGCATAGATGACAAC

(S) GATATCTCGGGTTTCCAACG

(AS) GGGCAGAGTCTGGTAGAATC

(S) TATCGGCCCACCCTGATGAG

(AS) GGATGCGGGCGTAGCAATAG

(S) CCTGGCCTTCATCAGTCTGG

(AS) GCGGTCACAGATGTACCTCC

(S) CTCTGCAAGACTGTGATAGC

(AS) TGGTTGCACAGGTGATATGG

(S) GCTTCATTGCAGTGGTTAGG

(AS) ATGATCTGTGGCAAGGAGAC

(S) CAGCCTCGTGCAGCATAACC

(AS) TGGACGTGTGGGCGAAGTAG
Amplicon

size (bp)

Annealing

temperature

$\left({ }^{\circ} \mathrm{C}\right)$

Efficiency

(\%)

Accession

number

or reference nd

135

161

91

147

167

177

123

116

146

144

166

166

100

303

165

444

185

176

147

187

157

124

155
NC_001961.1

JF802085.1

KJ127878.1

AY366525.1

Renson et al., 2017b

60

58

60

60

60

60

65

60

65

63

62

62

64

63

60.5

64

64

62

64

60

58.5

65
101

99

96

97

106

110

94

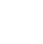

90

106

107

92

100

92

94

109

97

98

96

100

109

104
Nygard et al., 2007

Nygard et al., 2007

Meurens et al., 2009

Meurens et al., 2009

Meurens et al., 2009

Meurens et al., 2009

Meurens et al., 2009

Meurens et al., 2009

Meurens et al., 2009

NM_213876

Meurens et al., 2009

XM_013981570

XM_021086056

DQ157761

XM_003133655.4

XM_021075282.1

XM_003135179

DQ124104

XM_003129915

NM_001001623

XM_003133759 


\begin{tabular}{|c|c|c|c|c|c|c|c|c|}
\hline Group & $\begin{array}{l}\text { Alveolar septa } \\
\text { thickening }\end{array}$ & Airway material & $\begin{array}{c}\text { Peri- } \\
\text { bronchiolar and } \\
\text {-vascular } \\
\text { inflammation }\end{array}$ & $\begin{array}{l}\text { Alveolar } \\
\text { emphysema }\end{array}$ & $\begin{array}{l}\text { Proliferative } \\
\text { bronchitis }\end{array}$ & BALT & Jung score & $\begin{array}{l}\text { Composite } \\
\text { score }\end{array}$ \\
\hline Control 10 DPC & 3 & 1 & 1 & 1 & 0 & 0 & $42 \%$ & $29 \%$ \\
\hline Control 10 DPC & 0 & 1 & 2 & 1 & 0 & 0 & $25 \%$ & $19 \%$ \\
\hline Control 10 DPC & 3 & 1 & 0 & 2 & 0 & 0 & $33 \%$ & $29 \%$ \\
\hline Control 10 DPC & 3 & 2 & 2 & 1 & 0 & 0 & $58 \%$ & $38 \%$ \\
\hline Control 42 DPC & 2 & 0 & 2 & 1 & 0 & 0 & $33 \%$ & $24 \%$ \\
\hline Control 42 DPC & 1 & 1 & 1 & 2 & 0 & 0 & $25 \%$ & $24 \%$ \\
\hline Control 42 DPC & 1 & 2 & 1 & 2 & 0 & 0 & $33 \%$ & $29 \%$ \\
\hline Control $42 \mathrm{DPC}$ & 2 & 1 & 2 & 2 & 0 & 0 & $42 \%$ & $33 \%$ \\
\hline MLV1 10 DPC & 6 & 3 & 3 & 3 & 1 & 0 & $100 \%$ & $76 \%$ \\
\hline MLV1 10 DPC & 6 & 3 & 3 & 3 & 2 & 0 & $100 \%$ & $81 \%$ \\
\hline MLV1 10 DPC & 5 & 2 & 3 & 3 & 0 & 0 & $83 \%$ & $62 \%$ \\
\hline MLV1 10 DPC & 5 & 2 & 2 & 3 & 0 & 1 & $75 \%$ & $62 \%$ \\
\hline MLV1 42 DPC & 5 & 1 & 1 & 2 & 2 & 1 & $58 \%$ & $57 \%$ \\
\hline MLV1 42 DPC & 4 & 2 & 3 & 2 & 1 & 1 & $75 \%$ & $62 \%$ \\
\hline MLV1 42 DPC & 5 & 1 & 2 & 2 & 0 & 1 & $67 \%$ & $52 \%$ \\
\hline MLV1 42 DPC & 3 & 1 & 1 & 1 & 0 & 1 & $42 \%$ & $33 \%$ \\
\hline MLV1 42 DPC & 5 & 1 & 1 & 2 & 3 & 0 & $58 \%$ & $57 \%$ \\
\hline MLV2 10 DPC & 4 & 2 & 3 & 1 & 2 & 1 & $75 \%$ & $62 \%$ \\
\hline MLV2 10 DPC & 6 & 1 & 3 & 2 & 0 & 0 & $83 \%$ & $57 \%$ \\
\hline MLV2 10 DPC & 5 & 2 & 3 & 2 & 0 & 0 & $83 \%$ & $57 \%$ \\
\hline MLV2 10 DPC & 6 & 3 & 3 & 2 & 2 & 0 & $100 \%$ & $76 \%$ \\
\hline MLV2 42 DPC & 5 & 3 & 2 & 3 & 2 & 0 & $83 \%$ & $71 \%$ \\
\hline MLV2 42 DPC & 4 & 3 & 3 & 3 & 2 & 2 & $83 \%$ & $81 \%$ \\
\hline MLV2 42 DPC & 4 & 2 & 2 & 3 & 2 & 2 & $67 \%$ & $71 \%$ \\
\hline MLV2 42 DPC & 5 & 2 & 2 & 3 & 1 & 1 & $75 \%$ & $67 \%$ \\
\hline MLV2 42 DPC & 5 & 1 & 1 & 2 & 1 & 1 & $58 \%$ & $52 \%$ \\
\hline Fini 10 DPC & 5 & 1 & 2 & 3 & 0 & 0 & $67 \%$ & $52 \%$ \\
\hline Fini $10 \mathrm{DPC}$ & 5 & 0 & 2 & 3 & 0 & 0 & $58 \%$ & $48 \%$ \\
\hline Fini $10 \mathrm{DPC}$ & 6 & 2 & 2 & 3 & 1 & 0 & $83 \%$ & $67 \%$ \\
\hline Fini 10 DPC & 4 & 2 & 2 & 3 & 1 & 0 & $67 \%$ & $57 \%$ \\
\hline Fini 42 DPC & 6 & 3 & 3 & 3 & 0 & 0 & $100 \%$ & $71 \%$ \\
\hline Fini 42 DPC & 5 & 3 & 3 & 3 & 0 & 0 & $92 \%$ & $67 \%$ \\
\hline Fini 42 DPC & 6 & 2 & 3 & 3 & 0 & 0 & $92 \%$ & $67 \%$ \\
\hline NI 10 DPC & 3 & 2 & 3 & 2 & 0 & 0 & $67 \%$ & $48 \%$ \\
\hline NI 10 DPC & 3 & 2 & 3 & 3 & 0 & 0 & $67 \%$ & $52 \%$ \\
\hline NI 10 DPC & 2 & 2 & 3 & 2 & 0 & 0 & $58 \%$ & $43 \%$ \\
\hline NI 10 DPC & 5 & 3 & 2 & 2 & 0 & 0 & $83 \%$ & $57 \%$ \\
\hline NI 42 DPC & 4 & 1 & 2 & 3 & 0 & 0 & $58 \%$ & $48 \%$ \\
\hline NI 42 DPC & 4 & 1 & 2 & 2 & 0 & 0 & $58 \%$ & $43 \%$ \\
\hline NI 42 DPC & 5 & 1 & 2 & 2 & 0 & 0 & $67 \%$ & $48 \%$ \\
\hline NI 42 DPC & 4 & 1 & 2 & 2 & 0 & 0 & $58 \%$ & $43 \%$ \\
\hline
\end{tabular}

